\title{
MODERN PROBLEMS IN THE CONTRACT SYSTEM OF FEDERAL AND MUNICIPAL PROCUREMENT
}

\author{
Iolanta V. Baltutite \\ Volgograd State University, Volgograd, Russian Federation \\ Davud A. Davudov \\ Volgograd State University, Volgograd, Russian Federation
}

Introduction: federal procurement plays an important role in ensuring the progressive development of both the economic complex of the country as a whole and its individual regions. This is evidenced by the results of the analysis of the regional level for the individual sectors and segments of the economic complex, which confirm quite significant expenditures of the regional budgets for the federal and municipal procurement. At the same time, the economic practice of applying the contract system indicates certain shortcomings identified in the implementation of federal (municipal) procurement. Methods: the methodological framework for this study is the methods of scientific knowledge, among which the main are the methods of systematicity, analysis and comparative law. Results: the study is devoted to the existing problems of the legal regulation in the contract system. For feasible and practical update of all the legal rules it is necessary to create such an initial legislative base, which in the future you could start from, change and supplement, adhering not to a cardinal, but a gradual approach. Conclusions: as a result of the study it was found that in the Russian Federation a significant amount of public financial resources is spent to meet federal and municipal needs. The problem of the legal regulation of the domestic contract system is a fundamental element in the system of all the Russian legislation. Therefore, the Russian legislator needs to timely address these problems and fill in the missing moments to improve the contractual legal relations of the Russian Federation.

Key words: contract system, customer, federal and municipal procurement, methods of placing a state order, monitoring, audit, budget funds.

Citation. Baltutite I.V., Davudov D.A. Modern Problems in the Contract System of Federal and Municipal Procurement. Legal Concept, 2019, vol. 18, no. 1, pp. 105-111. (in Russian). DOI: https://doi.org/10.15688/ lc.jvolsu.2019.1.14

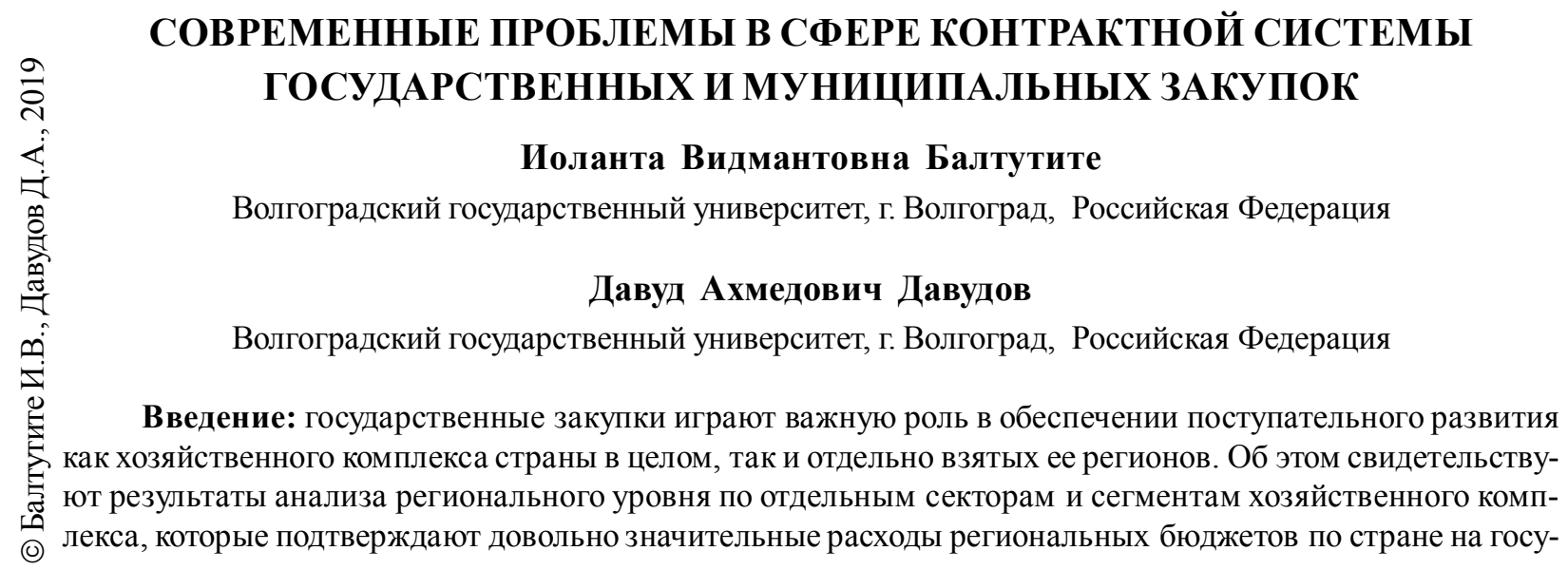


дарственные и муниципальные закупки. Вместе с тем хозяйственная практика применения контрактной системы указывает на определенные недостатки, выявленные в процессе реализации государственных (муниципальных) закупок. Методы: методологическую основу данного исследования составили методы научного познания, среди которых центральное место занимают методы системности, анализа и сравнительно-правовой. Результаты: данная статья посвящена существующим проблемам правового регулирования в контрактной системе. Для целесообразного и практичного обновления всех правовых норм необходимо создать такую первоначальную законодательную базу, от которой в будущем можно было отталкиваться, изменять ее и дополнять, придерживаясь не кардинального, а постепенного подхода. Выводы: в итоге проведенного исследования установлено, что в Российской Федерации для обеспечения государственных и муниципальных нужд расходуется значительный объем публичных финансовых ресурсов. Проблема правового регулирования отечественной контрактной системы является основополагающим звеном в системе всего российского законодательства. Следовательно, российскому законодателю необходимо своевременно подойти к данным проблемам и восполнить недостающие моменты для усовершенствования контрактных правоотношений РФ.

Ключевые слова: контрактная система, заказчик, государственные и муниципальные закупки, способы размещения государственного заказа, мониторинг, аудит, бюджетные средства.

Цитирование. Балтутите И. В., Давудов Д. А. Современные проблемы в сфере контрактной системы государственных и муниципальных закупок // Legal Concept = Правовая парадигма. - 2019. - T. 18, № 1. C. 105-111.-DOI: https://doi.org/10.15688/lc.jvolsu.2019.1.14

\section{Введение}

Государственные закупки товаров, работ, услуг для обеспечения государственных и муниципальных нужд - это конкурентная форма размещения заказов на покупку товаров, работ и услуг для нужд государства за счет бюджетных средств по заранее указанным в документации условиям в оговоренные сроки на принципах состязательности, справедливости и эффективности. Можно смело утверждать, что государственные закупки товаров, работ, услуг для обеспечения государственных и муниципальных нужд являются востребованной в современной экономико-правовой системе России конструкцией, что подтверждается неизменным ростом объемов финансирования в сфере обеспечения контрактной системы закупок.

Касаясь законодательства контрактной системы нашей страны в целом, можно говорить о ее стремительном расширении и изменении. На что уже было указано в предыдущих исследованиях, прогнозируются кардинальные изменения процедуры государственного заказа (в том числе полный переход на электронную основу). Также, затрагивая принципы контрактной системы РФ, можно говорить об их «несовершенности» в плане прозрачности и публичности. В связи с этим на первый план ставится сопоставление принципа прозрачности и способа реализации госу- дарственного заказа у единственного поставщика, что в некоторой степени затрудняет данную процедуру определения поставщика в свете открытости. Отсутствие конкурсной основы по своей природе предполагает отрицание признаков публичности, массовости и многочисленности, на которые указывает Ф3-44 от 05.04.2013 «О контрактной системе в сфере закупок товаров, работ, услуг для обеспечения государственных и муниципальных нужд» (далее - Ф3-44) [4, с. 13].

Также существует и негативное применение принципа открытости, заключающееся в открытом и бесплатном доступе к реестру недобросовестных поставщиков, так как заказчик по своему личному волеизъявлению вносит в данный реестр любые сведения о конкретном поставщике, что не исключает внесения ложных данных.

В таком случае для предотвращения нежелательных последствий в форме внесения неправдоподобной информации в государственный реестр поставщику необходимо оперативно предпринимать защитные меры. Необходимо предоставить факты, удостоверяющие форс-мажор. Чтобы доказать непреднамеренность своих действий, на неподписание государственного контракта должна быть уважительная причина. Ведение реестра недобросовестных поставщиков осуществляется Федеральной антимонопольной службой и ее территориальными органами [2, с. 120]. 
И.В. Балтутите, Д.А. Давудов. Современные проблемы в сфере контрактой системы закупок

Существует и проблема правового обеспечения Единой информационной системы (ЕИС), которая из-за технических сбоев и загруженности стала регулярно виснуть и выходить из строя в последнее время. Следовательно, наблюдается риск неисполнения государством своей социальной обязанности перед гражданами РФ. В связи с этим нужно тщательно подстраховаться во избежание подобных проблем и коллапсов.

Например, имеется ввиду разрешение на размещение сведений о закупочных процессах на региональном и муниципальном направлениях в системах заказчиков на личных Интернет-сайтах с перенесением данной информации в Единую информационную систему (ЕИС). Следовательно, существует необходимость проведения в ЕИС качественного мониторинга и контроля деятельности заказчика. Также можно избежать определенных проблем подобного рода путем полного задействования электронных площадок [1, с. 18].

Исходя из вышеизложенного и подкрепляя данные различными весомыми фактами, в ходе исследования были проведены тщательный анализ Ф3-44 и практика планирования и исполнения государственного заказа, в результате чего выделены несколько следующих его недоработок.

\section{Недостатки контрактной системы, выявленные в процессе реализации государственных (муниципальных) закупок}

Первая проблема заключается в том, что Ф3-44 устанавливает единые требования проведения закупочной деятельности для заказчиков всех уровней (федерального, субъекта и муниципалитета), что является некорректным для реализации государственного заказа, так как у различных заказчиков различная финансовая растрата. Следовательно, не всегда установленные жесткие рамки соблюдаются заказчиками, из-за чего возникают различные проблемы в виде появления третьих лиц, которые формально выигрывают в торгах и передают местным исполнителям уже готовые контракты, то есть происходит фальсификация документации государственного контракта.
Вторая проблема зиждется на противоречии принципов российской контрактной системы и самих норм Ф3-44, где предоставляется полная свобода участникам контрактных отношений и одновременно устанавливаются жесткие правила для ведения изучаемой процедуры (например, мониторинг конкурсных торгов, создание контрактной службы, банковская гарантия и другие). В результате этого заказчик может быть обвинен в нарушении российского законодательства и полностью понести юридическую ответственность.

Третья проблема отражает неполноту и несовершенство нормативно-правовой базы контрактной системы РФ. Участники государственного заказа в некоторых случаях собственноручно додумывают некоторые правила реализации закупок. Изначально отталкиваясь от ранее действующего, но ныне утратившего силу федерального закона о контрактной системе РФ (Федеральный закон «О размещении заказов на поставки товаров, выполнение работ, оказание услуг для государственных и муниципальных нужд» от 21.07.2005 № 94-Ф3), который с первых дней его существования подкреплялся целым массивом подзаконных актов, Ф3-44 подкрепляется «слабой» нормативной базой, включая всего лишь несколько постановлений правительства РФ.

Помимо этого, можно выделить следующие проблемы, касающиеся правового регулирования контрактной системы РФ.

Проблема комплексного использования всей процедуры контрактной системы, начиная от планирования государственного заказа и заканчивая нормированием, обоснованием закупки и созданием определенной документации. Контрактная система в целом является эффективным инструментом финансового снабжения только при комплексном использовании всех ее инструментов и методов. В настоящее время не все инструменты современной контрактной системы используются в полной мере (пример: выходит из строя единая информационная система, а официальный сайт государственных закупок работает с техническими перебоями).

Также наблюдается слабое звено в системе контроля и обжалования. По нашему мнению, система контроля, предусмотренная законом № 44-Ф3, является избыточной. Кро- 
ме контролирующей структуры, схожими функциями обладают общественный, финансовый и ведомственный контроль, а также прокурорская проверка. Реальное усложнение ситуации заключается в отсутствии ответственности лиц контролирующих органов. В силу своих интересов и выгоды данные лица посредством шантажа и необоснованных (ошибочных) жалоб давят на поставщиков для совершения каких-либо фальсифицированных противозаконных деяний.

В настоящее время отсутствует специальный орган по разьяснению законодательства о контрактной системе, что, в свою очередь, является минусом для правопонимания ее сути и точности процедуры реализации государственного заказа. Министерство экономического развития такими полномочиями не обладает. В качестве примеров указанной проблемы следует привести отсутствие единообразия, сложность координации и ограниченность подходов к централизации закупок. В ряде случаев передача закупок уполномоченным органам (учреждениям) приводит к недоучету потребностей заказчиков, несоответствующему их требованиям качеству закупочной деятельности. При этом на федеральном уровне в настоящее время уполномоченные органы (учреждения) отсутствуют, несмотря на положительный мировой опыт таких решений.

Несмотря на бурное развитие контрактной системы РФ, в настоящее время отсутствует единая подготовка и аттестация кадров. В соответствии с российским законодательством о контрактной системе члены закупочной комиссии и контрактной службы в обязательном порядке должны пройти определенную подготовку и квалификацию. В связи с этим в настоящее время появилось множество организаций по повышению квалификации служащих в сфере контрактной системы, которые выдают необходимую документацию за бесценок. В результате этого участились случаи мошенничества и коррупции, принцип профессионализма тоже в некоторой степени утратил свое место в качестве основополагающего начала.

Наблюдается и несбалансированность системы поощрения и наказания контрактных служащих, что является главным очагом взя- ток, текучести кадров и коррупционных явлений. Законодательство не предусматривает определенные поощрения, а штрафные санкции сопоставимы с размерами зарплат. Многочисленная судебная практика доказывает сказанное.

Что касается оценки эффективности работы контрактных служащих, то в данном случае она отсутствует [4, с. 76]. Поэтому представляются важными определение критериев эффективности, проведение регулярного и независимого аудита и принятие решений о корректировке контрактной системы на его основе. Несмотря на то что аудит предусмотрен законом 44-Ф3, пока он не в полной мере соответствует описанной задаче.

\section{Проблемы правового регулирования контрактной системы и возможные пути их решения}

Исходя из вышеизложенного, можно говорить о несовершенности 44-Ф3, а также о множестве проблемных моментов контрактной российской системы, которые необходимо урегулировать и незамедлительно устранить. Особое внимание следует уделить проблеме «информированности» субъектов малого и среднего бизнеса в отдельных тендеpax. Это связано с тем, что на официальном сайте государственных закупок происходит затрудненная регистрация для просмотра важной информации о закупках. Такая регистрация проходит в два затруднительных этапа: a) получение специального сертификата путем подачи отдельной документации (сведения о наличии определенного статуса лица) в Федеральное Казначейство Российской Федерации, б) установка на ПК определенного пакета веб-программ для дальнейшего пользования сайтом. Следовательно, необходимо упростить доступ к информационным ресурсам контрактной системы путем внесения на официальный сайт единой информационной системы в сфере закупок (zakupki.gov.ru) общего личного кабинета для упрощенной (демо-версии) регистрации желающих просмотреть необходимую информацию о предстоящих тендерах, далее, если тендер заинтересовал пользователя личного кабинета, необходимо пройти еще одну регистрацию, но только без 
установки различных программных обеспечений на ПК. Эти программы должны быть уже в электронном виде установлены в личном кабинете на официальном сайте государственных закупок.

На порталах государственного заказа имеются также и технические проблемы (сбои, выбивания). Информационные ресурсы не успевают вовремя обновляться, поэтому некоторые операции делаются вручную, на что затрачивается большое количество времени. $\mathrm{B}$ результате сложившейся ситуации за последние шесть месяцев резко снизилось число заявок на участие в тендерах и появились некоторые трудности для проверок заказчиков и производимых закупок, что привело к большому числу сговоров и нарушений контрактного законодательства. В связи с этим предлагается создать несколько информационных ресурсов для равномерного и бесперебойного приема информационных резервов, а также исключать неактуальную информацию о государственных заказах на интернет-архивах (на порталах государственных закупок).

Имеются некоторые «неясности» в закупочной российской деятельности в целом. Например, отсутствие уполномоченного органа для толкования нормативно-правовых актов контрактной системы РФ, в результате чего заказчик несет административную ответственность за неправильный выбор способа определения поставщика. Необходимо наделить уполномоченный орган такими полномочиями, поскольку он в целом производит полный мониторинг закупок и анализ нормативно-правовой документации по контрактной системе, а также после завершения проверок выносит соответственные обоснованные решения (например, различные стратегические показатели производимых закупок, решения по поводу мониторинга проведения контрактных процедур и др.).

Если вести речь и об определенных сведениях о недобросовестных участниках контрактных правоотношений, в п. 1.1 ст. 31 44-Ф3, установлено, что заказчик имеет право вносить сведения о недобросовестных поставщиках в определенный реестр, но только для юридических лиц (далее - ЮЛ). Закон «обходит» стороной физических лиц и индивидуальных предпринимателей, что является несомнен- ным «минусом» для российской контрактной системы, когда недобросовестные лица могут участвовать в закупочных отношениях. Предлагается включить в п. 1.1 ст. 31 44-Ф3 субъектов малого и среднего бизнеса, а также ЮЛ.

Наблюдается также, что полномочия контрактных управляющих, контрактных служб и комиссий по размещению государственных заказов в 44-Ф3 не разграничены, то есть они полностью совпадают (в ст. 38 ч. 4 44-ФЗ указывается, что полномочия контрактного управляющего заключаются в осуществлении организационных моментов закупки, исполнения контрактов и в их всестороннем обеспечении, такие же полномочия относятся и к закупочным комиссиям). В данном случае необходимо строго разграничить полномочия данных управляющих контрактных форм. К полномочиям контрактного управляющего должны относиться полномочия, которые уже регламентированы в ст. 38 ч. 4 44-Ф3: разработка планов закупок и плановграфиков, а также подготовка необходимой документации для закупочной деятельности и соответственно (в том числе составление претензионных писем и жалоб) осуществление закупок, заключение контракта, участие в рассмотрении дел, касающихся нарушений контрактного законодательства, проведение консультаций с участниками контрактных правоотношений. Последний пункт - «Иные полномочия контрактного управляющего» (ст. 38 44-Ф3) - необходимо полностью исключить для полной конкретизации полномочий должности. Контрактная служба должна ограничиваться только двумя полномочиями, а именно: а) проверка на соответствие закупочной деятельности исполнения контрактного законодательства; б) рассмотрение данных правонарушений. В ст. 39 44-Ф3 необходимо внести конкретные полномочия для комиссии по размещению государственных заказов, так как в этой норме содержится всего лишь описание данной организационной формы. Предлагаются следующие изменения в части полномочий такой комиссии: а) проверка заявок на участие в закупочной сфере; б) отклонение заявок, не соответствующих контрактному законодательству; в) выбор победившего поставщика. 
Проблемные моменты были обнаружены и в п. 3 ст. 94 44-Ф3, где описывается процедура исполнения контракта, указывается на проведение заказчиком экспертизы в любых случаях. В связи с этим в 44-Ф3 наблюдается отсутствие четкой регламентации правил проведения такой экспертизы. Кроме того, указанная процедура исключает главные особенности общих и отдельных видов закупок, что приводит к необоснованным экспертным решениям и повышеннию уровня коррупции. Необходимо внести поправки в части особенностей закупок, в их критерии и требования. Например, для благополучного проведения закупочной деятельности по перевозке пассажиров стоит установить осуществление любой перевозки без соискателей или третьих лиц. Такая «особенность» упоминалась и поддерживалась в Письме Министерства экономического развития Российской Федерации от 7 декабря 2015 г., № Д28и-3551.

Стоит также отметить, что необходимо ввести в 44-Ф3 новый раздел «По борьбе с коррупцией», где детально были бы расписаны меры по борьбе с коррупцией. Например, ввести различные способы влияния на «атмосферу» проведения контрактной деятельности: психологические (проведение различных глубинных тестов участников контрактных правоотношений), технические (создание специальных коммерческих каталогов закупок, оборудование переговорных комнат участников закупок и др.), регламентные (создание сводов определенных правил и контроль за их исполнением) и репрессивные (создание «неблагоприятной» среды для развития коррупционных отношений, например, установление различных финансовых барьеров и т. п.).

\section{Заключение}

Касаясь всех вышеизложенных проблем контрактной системы РФ, можно много говорить и об иных казусах правового регулирования, появляющихся по мере применения данных изучаемых закупочных процедур. Проблема правового регулирования отечественной контрактной системы является основополагающим звеном в системе всего российского законодательства, которому необходимо сво- евременно подойти к данным проблемам и восполнить недостающие моменты для усовершенствования контрактных правоотношений РФ.

В заключение отметим, что, несмотря на значительный ряд отрицательных моментов в данной сфере, также наблюдается и их устранение, и совершенствование контрактного законодательства в целом путем внесения законодателем различных новелл и нововведений. Думается, что в ближайшем будущем указанные проблемы будут устранены.

\section{СПИСОК ЛИТЕРАТУРЫ}

1. Алексеева, А. В. Становление и торможение контрактной системы в России / А. В. Алексеева // Актуальные проблемы экономики и общественного сектора. - 2017. - № 12.

2. Кохан, В. В. Основные проблемы в области правового регулирования государственных закупок, возможные пути их решения / В. В. Кохан // Молодой ученый. - 2017. - № 47. - С. 119-121.

3. Лычкова, А. Н. Проблемы правового регулирования контрактной системы РФ / А. Н. Лычкова // Российская газета. - 2017. - № 1.

4. Милина, И. А. Проблемы контрактного обеспечения / И. А. Милина // Аукционный журнал. -2017 . - № 9 .

\section{REFERENCES}

1. Alekseeva A.V. Stanovlenie i tormozhenie kontraktnoy sistemy v Rossii [Formation and Inhibition of the Contract System in Russia]. Aktualnye problemy ekonomiki $i$ obshchestvennogo sektora [Actual problems of the economy and the public sector], 2017, no. 12.

2. Kokhan V.V. Osnovnye problemy v oblasti pravovogo regulirovaniya gosudarstvennykh zakupok, vozmozhnye puti ikh resheniya [The Main Problems in the Field of Legal Regulation of Public Procurement, Possible Solutions]. Molodoy uchenyy [Young Scientist], 2017, no. 47, pp. 119-121.

3. Lychkova A.N. Problemy pravovogo regulirovaniya kontraktnoy sistemy RF [Problems of Legal Regulation of the Contract System of the Russian Federation]. Rossiyskaya gazeta, 2017, no. 1.

4. Milina I.A. Problemy kontraktnogo obespecheniya [Problems of Contract Support]. Auktsionnyy zhurnal [Auction Magazine], 2017, no. 9. 
И.В. Балтутите, Д.А. Давудов. Современные проблемы в сфере контрактой системы закупок

\section{Information about the Authors}

Iolanta V. Baltutite, Candidate of Sciences (Jurisprudence), Associate Professor, Department of Civil and International Private Law (Base Department of the Southern Scientific Center of Russian Academy of Sciences), Volgograd State University, Prosp. Universitetsky, 100, 400062 Volgograd, Russian Federation, u938om@yandex.ru, https://orcid.org/0000-0001-5443-2157

Davud A. Davudov, Candidate of Sciences (Jurisprudence), Associate Professor, Department of Civil and International Private Law (Base Department of the Southern Scientific Center of Russian Academy of Sciences), Volgograd State University, Prosp. Universitetsky, 100, 400062 Volgograd, Russian Federation, dav0587@mail.ru, https://orcid.org/0000-0002-1706-6124

\section{Информация об авторах}

Иоланта Видмантовна Балтутите, кандидат юридических наук, доцент кафедры гражданского и международного частного права (базовая кафедра ЮНЦ РАН), Волгоградский государственный университет, просп. Университетский, 100, 400062 г. Волгоград, Российская Федерация, u938om@yandex.ru, https://orcid.org/0000-0001-5443-2157

Давуд Ахмедович Давудов, кандидат юридических наук, доцент кафедры гражданского и международного частного права (базовая кафедра ЮНЦ РАН), Волгоградский государственный университет, просп. Университетский, 100, 400062 г. Волгоград, Российская Федерация, dav0587@mail.ru,https://orcid.org/0000-0002-1706-6124 